\section{Educación para el trabajo: ¿tenemos un sistema?}

Andrea Butelmann, Academica FEN UAH

La Comisión Nacional de Productividad (CNP), de cuyo consejo soy parte, ha sido mandatada a hacer recomendaciones con sido importante pero se ha postergado por décadas y ahora ha los constantes cambios tecnológicos, nos encontramos con una realidad desesperanzadora.

Una de las conclusiones que surgen es la necesidad de instalar un sistema de formación para el trabajo y dejar atrás lo que tenemos hoy: una serie de lineas de financiamiento de programas que no se articulan ni potencian entre si. En efecto, si bien hay intervenciones, tanto a nivel secundario como terciario, y programas de capacitación en el mapa de las políticas públicas, mejorar cada uno de ellos no hara gran diferencia, puesto que cada uno es un compartimiento estanco, lo que lleva a que se multipliquen esfuerzos (por ejemplo, para la detección de necesidades del sec-

tor productivo-), también a que no se aprovechen economías de estudio de distintos niveles no respondan a un criterio común ni preparen a los alumnos para el siguiente nivel. Además, no existe ante los 9000 programas técnico profesional a nivel terciario más de 160.000 códigos de cursos de OTEC diferenciados que capturan más de 250 millones de dólares de fondos públicos por la Franquicia Tributaria y que no hacen nada por el avance profesional de los trabajadores, y muchas otras falencias más

Lo que falta es un sistema de formación a lo largo de la vida para asegurar que las personas vayan acumulando y renovando sus competencias laborales, y que la enseñanza sea pertinente es decir, que responda a lo que demanda el sector productivo. Ta sistema debe estar articulado para que los conocimientos adquiridos en cualquier institución educativa o en el lugar de trabajo sean certificables al momento de proseguir una trayectoria educacional y laboral.

La ironia es que la implementación de tal sistema corresponde a una politica publica sofisticada, al igual que otras reformas fuerza laboral es analfabeta funcional $y$ los profesionales tampoco destacamos Cabe preguntarse entonces, si contamos con el capital humano necesario para implementar politicas de este tipo. En el siguiente gráfico se aprecia el bajo porcentaje de adultos que alcanzan los más altos niveles de comprensión lectora en prueba PIACC y el panorama desolador en que ese porcentaje en Chile para el grupo con educación terciaria es menor que para población con educación secundaria en el promedio OECD.

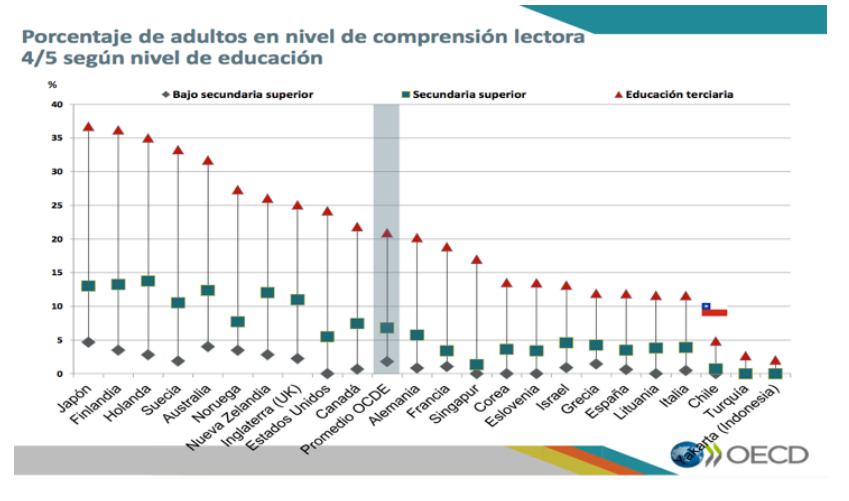

Este nivel de analfabetismo funcional distorsiona el uso de nuestros recursos humanos. En el estudio sobre productividad minera de la CNP, resalta el hecho que, en las grandes minas de cobre en Chile, el 75\% de los supervisores son ingenieros. En paises desartlados, solo el $25 \%$ de los supervisores son titulados universitarios, el resto son trabajadores que han logrado progreJustamente a nuestras deficiencias lecto-escritoras ya que una parte del trabajo del supervisor es reportar por escrito y seguir protocolos Asi, tenemos muchachos recién egresados de la universidad a cargo de trabajadores mayores, con más experiencia y frustrados por el techo con el que topan en sus carreras.

LA EDUCACIÓN TÉCNICO PROFESIONAL

Si bien creo que toda educación es para el trabajo, entendiendo trabajo como la obra humana, el analisis de la Comisión se ha centrado en la educación tecnica profesional -mediay yuperior-y en la capacitación de los trabajadores. Alrededor del 40\% de los grasados de educación media corresponde a alumnos de programas técnico- profesionales.

Algunos eligen la educación técnica por vocación o porque su metodologia de enseñanza es más atractiva; sin embargo, para la mayorím la elección queda determinada por un bajo rendimiento buir a su manutención ambas condiciones relacionadas a su nivel socioeconómico. En efecto el 56\% de los niños en liceos técnicos (EMTP) tienen padres que no han terminado la educación secundaria, lo que se compara con un 23\% de los que van a educación. cientifico humanista (EMCH).

Esta segunda oportunidad de alcanzar mayores niveles de equi-
aad y productividad se ve frustrada por la poca importancia que el país le ha dado a este tipo de educación, lo que se evidencia en la subvención escolar que no da cuenta de los mayores costos para medir sus resultados profesional', tampoco existen esfuerzos enseñanza queda a cargo del Ministerio de Educación que diseña los programas, los que no se renovarian con la frecuencia ni co el nivel de participación del sector productivo deseables. La condición socio-económica de tales alumnos produce trayectorias distintas a las de sus pares que egresan de EMCH. En efecto, siguiendo en el tiempo a la cohorte que egreso de la ensesados de liceos técnicos eventualmente ingresan a la edución superior (63\% vs 90\% de los egresados de EMCH) muy pocos 10 hacen inmediatamente; trabajan primero y van incorporándose gradualmente a la educación terciaria, tal como lo indica la tabla 1 y tienen mayor probabilidad de combinar estudios $y$ trabajo. Además, el 70\% va a la educación terciaria de tipo técnico, mientras que entre los egresados de EMCH ese mismo porcentaje sique estudios universitarios. Estos jóvenes, muestran una mayor probabilidad de cambiarse de carrera, lo que subraya la necesidad de mejorar la información sobre contenidos y proyecciones laborales de cada carrera y la orientación vocacional. También evidencia la importancia de que lo cursado en una carrera se pueda portar a otra sin necesidad de empezar desde cero, si tienen aprendizajes comunes.

Dada la caracterización, concluimos que es crucial que los lecto-escritura matemáticas uso de software- legar a a educaión terciari en condiciones de aprovecharla con competencias laborales suficientes, dado que lo más probable es que deban trabajar en algún momento antes de graduarse del nivel terciario. Tales competencias laborales no deberían ser muy especificas a un sector económico sino que tendrian que prepararlos en habilidades transversales y blandas que le permitan trabajar mientras se perfeccionan en el área que han escogido dentro de una rango mayor de alternativas y en forma más informada que cuando escogieron especialidad en la EMTP.

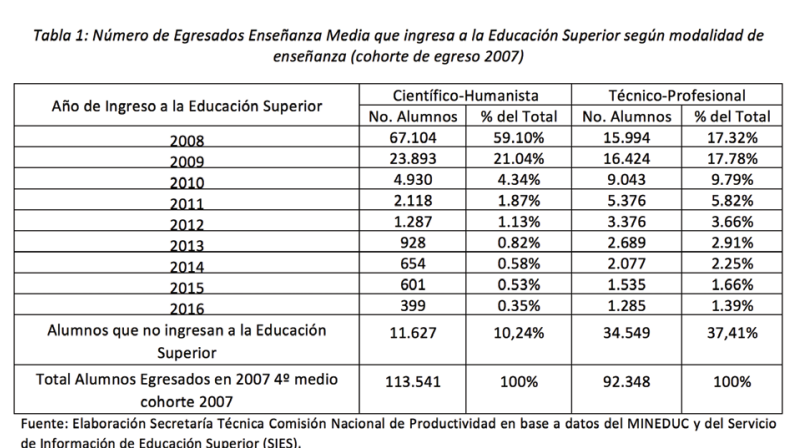

En el caso de la TP a nivel terciario, que es la opción más freEnente para los egresados de EMTP, también nos encontramos con problemas. Desde ya la multiplicidad de carreras con distintos nombres introduce muchisima opacidad y dificulta las decisiones tanto para el joven al momento de elegir su carrera como para el empleador para reconocer qué competencias adquiere el egresado de cada programa.
Adicionalmente, hay competencias que se adquieren justamente en la experiencia laboral y es importante que se puedan

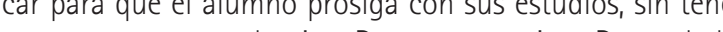
que cursar temas que ya domina. Pero eso no existe. Por un lado. las carreras son rigidas y más que determinar los aprendizajes ad de insumos, -horas de clases-. En cuanto a la pertinenci de ${ }^{2}$ ios, -horas de clases-. En cuanto a la pertinencia ector productivo, pero son realizados por cada institución y no enefician al sistema educativo en su conjunto.

En cuanto al financiamiento, nos encontramos otra vez con ta eca importancia que se le da a la educación técnico profesiona nivel terciario reflejado en la Tabla 2.

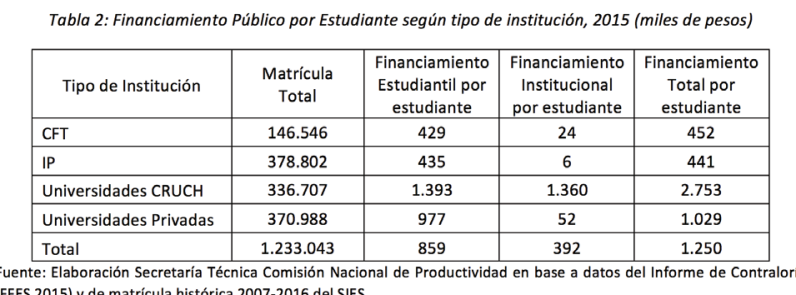

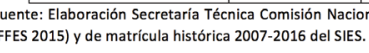

Todo lo expuesto resulta en una baja tasa de titulación. En cono educación media, sólo el 25\% de los egresados de EMTP habí ogrado titularse del nivel terciario, lo que se compara con un $47 \%$ de los que egas.
carreras más largas.

Por último es necesario repensar el rol de la franquicia tributaila y otros programas del SENCE. El mayor gasto en capacitación enile es el que se destina a la franquicia tributaria, mediante capacitación hasta el 1\% de su planilla. Este sistema fue pensado 政 encias de las que carecian sus trabajadores cilion capacitación tendría mayor pertinencia y en calidad como en pertinencia

Por tanto se requiere un sistema que coordine todos los esfuerzos y permita a cada individuo adquiri las competencias bborales que le interesen y que el mercado demande, en distintos momentos de su trayectoria laboral acorde a los cambios tecnológicos y las consecuentes alteraciones en la estructura productiva del pais. Este sistema sólo podrá funcionar si tiene una gobernanza comun a todos los niveles educativos y tenga poder portico suficiente para articularlos. Al comparar la posición en e organigrama publico del ente encargado de este rol en Chile versus su posición en paises en que el sistema funciona adecuadamente, la verdad es que dan ganas de llorar. Si además pensamos urgencia de los cambios.

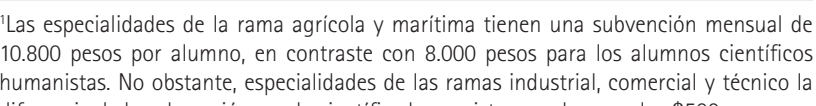
En efecto, al tercer año de earesados de $E M$, un 320 d de los inscritos en en educación supe-

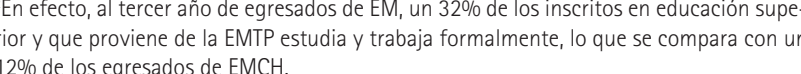

